\title{
Effect of Purple Sweet Potato on Hair Dyeing and Hair Texture Improvement
}

\author{
Ju-Sub Kim \\ Department of Beauty Design, Sangji University, Wonju-si, Gangwon-do, Korea
}

\author{
Corresponding author: Ju-Sub Kim, \\ Department of Beauty Design, Sangji \\ University, 84 Sangjidae-gil, Wonju-si, \\ Gangwondo 26339, Korea \\ Tel.: +82 337300811 \\ Fax: +82 337300811 \\ Email: c-miro@hanmail.net
}

Received June 29, 2020

Revised July 13, 2020

Accepted July 16, 2020

Published September 30, 2020

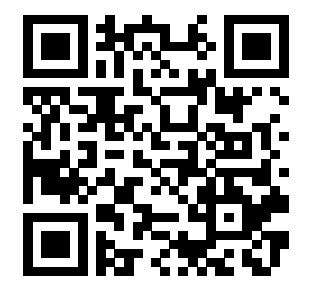

\begin{abstract}
Purpose: This study aimed to find out if the purple sweet potato could be used as a natural hair dye. It tried to examine its effect by producing a hair texture improvement agent with purple sweet potato powder containing anthocyanin. Methods: A hair texture improvement agent using different concentrations of purple sweet potato powder like $0 \%, 6 \%, 9 \%$, and $12 \%$ was produced. After applying the improvement agent to a bleached sample hair, it was heated and left in natural condition. Then, a comparative analysis between an experimental group and a control group was conducted. To understand the effect of hair dyeing, the values of Color-difference and the degree of fading were measured using a color difference scale. Also, to understand the dyeing effect on hair texture improvement, we measured the absorbance and luster using tensile strength and methylene blue. Results: The $L^{*}$ value in level 7 of the experimental group decreased when purple sweet potato concentration increased. The increase in $a^{*}$ and $b^{*}$ was not significant compared to the control group. Also, the $\Delta \mathrm{E}^{*}$ increase was not significant compared to the bleached hair. The experimental group in level 9 showed no fading on the third day. Further, the experimental group did not show significant tensile strength increase compared to the control group. Additionally, the experimental group showed an absorbance decrease in comparison with the control group. Finally, the experimental group's luster was significantly lower compared to the control group. Conclusions: The hair texture improvement agent produced with purple sweet potato powder did not show a significant effect on hair dyeing and hair texture improvement. More studies should be carried out before its probable commercialization.
\end{abstract}

Keywords: Purple sweet potato, Hair, Dye effect, Hair texture, Damage

\section{Introduction}

모발 손상을 자체를 방지하거나 손상 정도를 낮추기 위해서 많은 연구가 이루어지고 있다. 모발의 손상 요인으로는 물리적인 요인, 화 학적인 요인이 있을 수 있다. 물리적인 요인보다는 화학적인 요인에 의해 모발의 손상이 더 야기된다. 물리적인 손상의 주요 원인으로 퍼 머넌트웨이브, 염색, 탈색에 의한 모발 손상이 심하게 야기된다. 이 러한 화학적인 요인 중에서 염색에 의한 손상을 줄일 수 있는 방법에 대한 연구가 계속되고 있다. 그 중에서도 화학적인 염료에 의한 손 상을 대체 할 천연 염색 원료에 대한 연구가 이루어지고 있다. 상업 적인 염색과 합성염료가 광범위하게 사용되고 있음에도 불구하고 천
연 염료의 사용에 대한 관심은 지속적으로 증가하고 있다. 천연 염료 의 생산 및 시장, 염색의 안전성 및 인체 적합성 등에 대한 연구가 지 속적으로 필요하다. 일반적인 화학 원료의 염색 시술 시 두피의 부작 용 및 모발에 손상을 야기 시키기도 한다(Jeong et al., 2012). 염모 제는 헤나와 같이 천연 염료와 화학 성분인 합성 염모제로 크게 구분 할 수 있다(Kim et al., 2006). 두피와 모발에 손상을 야기하는 것을 방지하기 위해 두피의 염증 유발을 적게 하는 천연물질 연구가 이루 어지고 있다(Kim, 2014a). 또한 천연 염료를 이용한 모발 염색 연구 (Oh \& Jung, 2017), 천연치자 황색소와 전해수를 이용한 모발의 염 색 및 변화 연구(Yoo \& Choi, 2017), 자색고구마의 모발에 대한 천 연염색 원료 연구(Kim \& Yoo, 2019), 녹차씨 오일이 염색 및 탈색 
된 모발에 재 손상 및 탈색 방지에 미치는 영향(Min et al., 2013), 이렇듯 모발 손상을 방지하기 위해 성분에 대한 처리에 의한 모발의 염색성과 형태적 특성에 미치는 영향에 수요가 커지고 있다(Kim \& Kwon, 2008). 모발의 손상을 낮추고 염색 효과를 동시에 보고자 천 연 색소인 자색고구마 분말을 모발에 도포하여 그 효과를 보고자 한 다. 고구마에는 $\beta$-카로틴, 안토시아닌, 폴리페놀, 강글리오사이드 등과 같은 기능성 성분이 존재가 보고되고 있으며(Lee et al., 2007), 특히 표피와 육질이 진한 자색을 띠는 자색고구마는 높은 안토시아 닌 색소를 함유하고 있으며, 항산화, 간기능 보호 등 기능이 보고 되 어 있다(Choi et al., 2000; Kim et al., 2015). 자색고구마의 연구는 주로 식품과 관련된 연구가 진행되어 왔다. 자색고구마에 풍부한 안 토시아닌 색소가 모발에 염색이 되어 지고 모질의 개선 변화에 영향 을 주는지에 대해 알아보고자 한다.

모발 염색에 사용되는 원료인 자색고구마로 천연염색을 시술하기 위해서는 자색고구마 분말을 첨가한 모발 제품을 제조하거나, 자색 고구마 분말 자체를 모발에 도포하여 염색 효과를 연구할 수 있다. 그러나 염색 효과와 모질의 개선 변화를 알기 위하여 본 연구에서는 자색고구마 분말을 함유한 트리트먼트 개념의 제품을 제조하여 연구 하고자 한다. 이러한 제조를 한 이유는 자색고구마의 염색 효과와 모 질의 개선효과가 탁월 할 시 상용화를 염두에 두어 연구하고자 한다.

따라서 본 연구는 안토시아닌 성분이 함유된 자색고구마 분말로 모질 개선제를 제조하여 천연염색의 원료로 사용가능한지를 알아보 고자 하였다. 자색고구마의 염색 효과를 연구하고, 모질의 개선에 영 향을 주는지를 알아보고자 하였다. 자색고구마 분말을 함량 별로 다
르게 제조하여 염색 효과를 알기 위해 모발 시료에 도포한 후 시료의 염색 효과와 물 빠짐을 측정하고, 또한 인장강도, 메틸렌블루를 이용 한 흡광도 측정, 광택을 측정하여 모질의 개선 정도를 알아보고자 하 였다.

\section{Methods}

\section{1. 실험재료}

\section{1) 시료 모발}

실험을 위하여 사용된 모발은 최근 2 년 동안 약물복용과 화학적 시술을 하지 않은 18 세 여성의 모발을 후두부에서 두피 $3 \mathrm{~cm}$ 지점 을 기준으로 $20 \mathrm{~cm}$ 로 채취하여 $2 \mathrm{~g}$ 씩 모(hair) 다발을 만들고 $\mathrm{pH}$ 7.0 의 중성 샴푸로 세척, 자연건조 하여 사용하였다. 이후 자색고구 마의 염색 효과를 확인하기 위하여 건강모와 이 건강 모발에 탈색 제 제1제(ammonium persulfate, potassium persulfate, sodium metasilicate, magnesium, sodium carboxymethyl cellulose) (Suanhj, Korea) $3 \mathrm{mg}$ 과 제2제(6\%의 과산화수소를 주성분으 로 water, etidronic acid, phosphoric acid, sodium phosphate dibasic, cetyl alcohol로 구성된 제품) (Suanhj, Korea) $3 \mathrm{~mL}$ 비율 로 혼합하여 도포하고 $30 \mathrm{~min}$ 방치 후 세척하여 명도 7레벨의 시료 를 제작하여 대조군(control group)으로 하였다. 명도차에 의한 비 교를 위해 9 레벨의 시료도 만들었으며 2 번의 탈색을 하였다. 실험에 사용된 모발 시료의 level 측정기(level scale, Wella, Germany) 사용

\section{Table 1. Composition of hair-treatment agent}

\begin{tabular}{|c|c|c|c|}
\hline No & Ingredients & Content (\%) & Function \\
\hline 1 & Water & 84.230750 & Solvent \\
\hline 2 & Cetyl alcohol & 3.545000 & Emulsion stabilizer \\
\hline 3 & Propylene glycol & 2.700000 & Conditioning agent \\
\hline 4 & Cyclopentasiloxane & 2.500000 & Conditioning agent \\
\hline 5 & Stearamidopropyl dimethylamine & 1.500000 & Antistatic agent \\
\hline 6 & Steartrimonium chloride & 1.300000 & Conditioning agent \\
\hline 7 & Stearyl alcohol & 1.150000 & Emulsion stabilizer \\
\hline 8 & Cetrimonium chloride & 0.870000 & Antistatic agent \\
\hline 9 & Behentrimonium chloride & 0.800000 & Antistatic agent \\
\hline 10 & Ethoxydiglycol & 0.362500 & Solvent \\
\hline 11 & Citric acid & 0.300000 & pH adjuster \\
\hline 12 & Myristyl alcohol & 0.240000 & Emulsion stabilizer \\
\hline 13 & Isopropyl alcohol & 0.200000 & Solvent \\
\hline 14 & Ethylene glycol & 0.136750 & Solvent \\
\hline 15 & Disodium EDTA & 0.100000 & Chelating agent \\
\hline 16 & Lauryl alcohol & 0.065000 & Emulsion stabilizer \\
\hline
\end{tabular}


하였으며 level 측정은 미용 현장에서 $8 \mathrm{yr}$ 이상 근무한 전문가 3 인이 측정하였다. 측정된 시료를 실험에 사용하였다. 이 시료에 자색고구 마 분말을 함량 별로 달리하여 제조한 모질 개선제를 도포한 모발 시 료를 실험군(experiment group)으로 하였다.

\section{2) 자색고구마 분말 색소}

본 실험에 사용한 자색고구마 분말 색소는 자색고구마 $100 \%$ 분말 (Qingdao Huikang Import \& Export co., Ltd, China)을 구입하여 사용하였다.

\section{3) 모질 개선제 제조}

본 실험에 사용한 모질 개선제는 (주)수안향장(Korea)에서 제조한 것으로 모든 시술에서 사용하였으며, 모질 개선제 조성표는 Table 1 과 같다. 자색고구마 분말을 $0 \%, 6 \%, 9 \% 12 \%$ 로 함량을 다르게 하여 제조하였다.

\section{4) 측정기기 및 측정방법}

(1) 염색 효과 표면 색상 $\left(\mathrm{L}^{*}, \mathrm{a}^{*}, \mathrm{~b}^{*}, \Delta \mathrm{E}\right)$ 측정

함량 별로 자색고구마 분말이 함유된 개선제로 도포한 실험군과 자색고구마 분말을 함유 하지 않은 개선제를 도포한 대조군의 표면 색상 변화를 알아보고자 색차계(Color meter, CS-10; CHN spec, China)를 이용하여 CIELAB 표색계의 색상 값인 명도지수 $\mathrm{L}^{*}$ 과 색 좌표 지수인 $\mathrm{a}^{*}$ 와 $\mathrm{b}^{*}$ 값을 측정하였다. 이때 광원과 광측 조건은 $\mathrm{D} 65 / 10^{\circ}$ 의 조건이었다.

$\mathrm{L}^{*}$ : CIELAB 표색계의 white-black 축에서의 명도지수

$\mathrm{a}^{*}$ : CIELAB 표색계의 red-green 축에서의 채도지수

$\mathrm{b}^{*}$ : CIELAB 표색계의 yellow-blue 축에서의 채도지수

$\Delta \mathrm{E}^{*}$ : 색의 정도 차이, 절대 색 좌표의 차이

측정값의 신뢰성을 높이기 위해 5 번 측정하여 최고 값과 최저 값 을 제외한 나머지 갑의 평균을 구하였다.

\section{(2) 물 빠짐 측정}

물 빠짐 측정 방법은 탁도계(Turbidity meter, TU-2016; Lutron electronic, Taiwan) 기기를 이용하여 자색고구마로 염색한 실험군 을 측정하였다. $200 \mathrm{~mL}$ 비이커에 정제수를 넣고 시료를 담근 후 탁
도를 측정하였다. 측정 기간은 3 일로 $24 \mathrm{~h}$ 주기로 측정하였다. 물 빠 짐 측정을 위해서는 모든 실험군을 사용하지는 않고, 가장 명도가 높 은 9레벨의 실험군으로 물 빠짐 측정을 하였다.

\section{(3) 인장강도 측정}

모질의 개선 정도를 알기 위해 함량 별로 자색고구마 분말로 도 포한 실험군과 자색고구마 분말이 함유되지 않은 개선제로 도포 한 대조군의 인장강도 측정 기기는 (Digital force gauge, HF-20; Tripod, China)로 인장강도를 측정하였다. 측정값의 신뢰성을 위하 여 5 회측정 후 측정값 중 제일 높은 값과 제일 낮은 값을 제외한 남 은 측정값의 평균값을 구하였다.

\section{(4) 메틸렌블루를 이용한 흡광도 측정}

모질의 개선 정도를 알기 위해 함량 별로 자색고구마 분말을 함 유한 개선제로 염색한 실험군과 자색고구마 분말이 함유되지 않 은 개선제로 도포한 대조군의 외경은 마이크로미터(Quickmike, Mitutoyo)를 이용하여 0.070-0.075 m의 굵기 오차범위를 정하 고 $5 \mathrm{~cm}$ 의 길이로 3 가닥 잘랐다. 3 가닥의 모발을 tube에 넣은 후 $\mathrm{MB}$ solution에 담가 vortex mixer (Vortex genie 2, Scientific Industries, USA)를 이용하여 $10 \mathrm{~s}$ 동안 vortexing하였다. $50^{\circ} \mathrm{C}$ heat block (wise therm HB-48P; Daihan Scientific, Korea)에 서 $10 \mathrm{~min}$ 간 유지하여 $\mathrm{MB}$ solution을 흡착시키고, tube에 있는 3 가닥의 시료를 꺼내어 표면에 묻어있는 $\mathrm{MB}$ solution은 실험용 티슈 를 이용하여 제거하고, 시료 한 가닥씩 새 tube에 옮긴다. 다시 tube 에 NR desorb solution을 $5 \mathrm{~mL}$ 를 넣고 상온에서 $5 \mathrm{~min}$ 방치 후 10 s vortexing 후 추출하였으며, 추출한 용액을 큐벳(cuvettes)에 3000 $\mu \mathrm{L}$ 분주하여 $\mathrm{MB}$ 의 흡수 강도가 가장 높은 파장인 $660 \mathrm{~nm}$ 로 흡광 도를 측정하였다. 1 회 추출 후 같은 방법으로 총3회 분광광도계(Vis spectrophotometer, SV1200; Azzota, USA)로 흡광도를 측정하 고 그 값의 평균을 구하였다. 측정 시 기준 값을 잡기 위해 desorb solution을 $3000 \mu \mathrm{L}$ 분주하여 blank를 만들어준다. $\mathrm{MB}$ 시약은 $\mathrm{DW}$ $20 \mathrm{~mL}+\mathrm{MB} 400 \mu \mathrm{L}$ 으로 희석하여 $2 \%$ 로 만들어 사용하였다. $\mathrm{NR}$ solution은 $49 \%$ ethanol $(49 \mathrm{~mL})+1 \%$ glacial aceticacid $(1 \mathrm{~mL})+$ $50 \% \mathrm{DW}(50 \mathrm{~mL})$ 의 비율로 완성하였다.

(5) 대조군과 실험군 광택 측정

\section{Table 2. Samples' dye treatment scheme}

\begin{tabular}{ll}
\hline Sample & \multicolumn{1}{c}{ Content } \\
\hline Virgin hair & Undamaged hair \\
Purple sweet potato 7 level $0 \%$ & Treatment of level-7 sample with Purple sweet potato 0\% dye \\
Purple sweet potato 7 level $6 \%$ & Treatment of level-7 sample with Purple sweet potato $6 \%$ dye \\
Purple sweet potato 7 level $9 \%$ & Treatment of level-7 sample with Purple sweet potato $9 \%$ dye \\
Purple sweet potato 7 level $12 \%$ & Treatment of level-7 sample with Purple sweet potato $12 \%$ dye \\
Purple sweet potato 9 level $12 \%$ & Treatment of level-9 sample with Purple sweet potato $12 \%$ dye \\
\hline
\end{tabular}


함량 별로 함유한 자색고구마 분말로 염색한 실험군과 자색고 구마 분말이 함유되지 않은 개선제로 도포한 대조군의 광택 변화 를 알아보고자 광택계(Gloss meter NHG268; Shenzhen Threenh Technology, China)를 이용하여 측정하였다. 측정값의 신뢰성을 높 이기 위해 5 번 측정하여 최고 값과 최저 값을 제외한 나머지 갑의 평 균을 구하였다.

\section{5) 도포 실험방법}

건강모와 탈색 시술한 시료 레벨 7레벨, 9 레벨 시료를 제작하였 다. 자색고구마 분말을 $0 \%, 6 \%, 9 \%, 12 \%$ 함량을 첨가한 모질 개선 제를 제조하여 각각의 시료에 $15 \mathrm{~g}$ 도포하였다. 시료 레벨 별로 도포 한 후 열처리 $10 \mathrm{~min}$ 과 자연건조 $10 \mathrm{~min}$ 후에 세척하여 자연 건조 후 측정하였다. 염색 도포는 염색 효과의 차이는 색소 함량, 도포량, 자연방치시간, 열처리 시간, 시술자의 숙련도에 등에 따라서 염착 효 과의 차이가 다를 수 있기 때문에 최대한 차이를 줄이기 위해 시술자 는 각 단계별로 동일인이 시술하였다. 각 자색고구마의 함량에 따른 시료 표기는 Table 2 와 같다.

\section{Results and Discussion}

\section{1. 자색고구마 분말 함량에 따른 실험군의 염색 효과 측정}

모발 손상을 줄이기 위한 방법으로 천연 염모제의 연구 개발이 꾸 준히 이루어지고 있다. 천연 성분인 자색고구마 분말 색소를 함량을 $0 \%, 6 \%, 9 \%, 12 \%$ 달리하여 제조한 모질 개선제를 실험군에 도포하 여 염색 효과를 알아보고자 연구하여 다음과 같은 결과를 얻을 수 있 었다.

\section{1) 실험군의 $L^{*}$ 측정}

자색고구마 분말 색소를 $0 \%, 6 \%, 9 \%, 12 \%$ 함량 별로 제조한 모 질 개선제로 도포한 후 열처리 $10 \mathrm{~min}$ 과 자연방치 $10 \mathrm{~min}$ 후에 모 발의 표면 색상 분석 결과 $\mathrm{L}^{*}$ 값은 Table 3 과 같다.

$\mathrm{L}^{*}$ 은 밝기인 명도(lightness)를 표현하는 수치로 0에서 100사이의 수치로 표시한다. 이때 0 은 black을 나타내고, 100은 white를 나타
낸다. 자색고구마분말을 함유한 개선제로 도포한 모발의 $\mathrm{L}^{*}$ 값은 대 조군(7레벨 자색고구마 분말 $0 \%$ 함유)와 비교하여 각각의 7레벨에 서 $6 \%, 9 \%, 12 \%$ 함유한 실험군의 L* 값은 감소하는 것을 확인 할 수 있다. 같은 레벨에서 자색고구마 분말 함량이 많을수록 L*값은 감소 하는 것을 확인 할 수 있었고 감소폭은 미비하게 나타났다. 미비한 감소 폭은 자색고구마 분말 함량이 증가함에 따른 결과로 사료된다. 건강모보다는 실험군의 $\mathrm{L}^{*}$ 값은 모두가 큰 차이로 증가하였다. 이는 탈색의 결과로 사료된다.

9 레벨에 $12 \%$ 함유한 실험모에서는 $\mathrm{L}^{*}$ 값이 대조군 보다 23.73 차 이로 증가함을 확인 할 수 있었다. 이 결과는 모발의 레벨이 높을수 록 큰 차이는 아니지만 $\mathrm{L}^{*}$ 값이 증가한 것으로 나타났다. 또한 같은 $12 \%$ 함량이지만 7레벨 실험군보다 9레벨 실험군의 값이 25.07 차이 로 증가하였다. 이는 모발 시료의 바탕 레벨이 높을수록 명도가 높아 진다는 Kim (2018)과 Jang \& Park (2015)의 연구결과와 같은 결과 이다.

2) 실험군의 $a^{*}, b^{*}$ 측정

자색고구마 분말 색소를 함량을 $0 \%, 6 \%, 9 \%, 12 \%$ 달리하여 제조 한 모질 개선제로 실험군에 도포하여 모발의 표면 색상 분석 결과 $\mathrm{a}^{*}$ 와 $\mathrm{b}^{*}$ 값은 Table 4 와 같다.

자색고구마분만을 함량 별로 다르게 제조하여 7레벨에 도포한 모 발의 $\mathrm{a}^{*}$ 값은 대조군(7레벨 자색고구마 분말 $0 \%$ 함유)보다 모두 $\mathrm{a}^{*}$ 값이 + 로 미비하지만 증가 되었다. 그러나 9 레벨 도포한 모발의 $\mathrm{a}^{*}$ 값은 대조군보다 $\mathrm{a}^{*}$ 값이 감소 되었다. 이는 7 레벨과 9 레벨의 차이로 사료되며 9 레벨의 명도를 얻기 위해 탈색을 2 번하였다. 이는 염모제 원리인 모표피 사이로 염색소가 침투한다는(Kim, 2017)의 내용과 같이 손상된 모표피, 모피질 사이로 자색고구마 분말이 많이 침투한 결과로 사료된다.

자색고구마분만을 함량 별로 다르게 제조하여 7레벨에 도포한 실 험군의 $b^{*}$ 값은 대조군보다 모두 $b^{*}$ 값이 + 로 미비하지만 증가 되었 다. 그러나 9 레벨 도포한 실험군의 $b^{*}$ 값은 대조군보다 $b^{*}$ 값이 감소 되었다. 이는 $\mathrm{a}^{*}$ 값이 감소한 이유와 같다고 사료된다. 건강모와 비 교 시 실험군의 $a^{*}$ 와 $b^{*}$ 값은 모두 증가하였다.

Table 3. Brightness $L^{*}$ value

\begin{tabular}{|c|c|c|c|c|c|c|}
\hline Sample & Virgin hair & 7 level 0\% & 7 level 6\% & 7 level 9\% & 7 level $12 \%$ & 9 level $12 \%$ \\
\hline$L^{*}$ value & 5.43 & 33.10 & 32.71 & 31.81 & 30.76 & 55.83 \\
\hline Sample & Virgin hair & 7 level 0\% & 7 level 6\% & 7 level 9\% & 7 level $12 \%$ & 9 level $12 \%$ \\
\hline$a^{*}$ & 0.34 & 14.15 & 15.35 & 15.89 & 16.74 & 12.40 \\
\hline$b^{*}$ & 1.13 & 27.66 & 27.84 & 27.88 & 27.97 & 22.69 \\
\hline
\end{tabular}

Table 5. $\Delta \mathrm{E}^{*}$ value

\begin{tabular}{lcccccc}
\hline Sample & Virgin hair & 7 level 0\% & 7 level $6 \%$ & 7 level 9\% & 7 level $12 \%$ & 9 level $12 \%$ \\
$\Delta \mathrm{E}^{*}$ value & 13.84 & 30.48 & 32.91 & 31.21 & 30.88 & 42.42 \\
\hline
\end{tabular}


3) 실험군의 $\Delta \mathrm{E}^{*}$ 측정

$\Delta \mathrm{E}^{*}$ 값은 색의 정도 차이, 절대 색 좌표의 차이를 말한다. 이는 두 가지 색의 차이, 방향의 차이는 알 수 없지만 색차를 한가지 수치 로 나타낸 것이다. 자색고구마 분말을 함량을 $0 \%, 6 \%, 9 \%, 12 \%$ 달 리하여 로 제조한 모질 개선제로 모발 시료에 도포하여 모발의 표 면 색상 분석 결과 $\Delta \mathrm{E}^{*}$ 값은 Table 5 와 같다. 자색고구마 분말을 함 량 별로 다르게 제조하여 7 레벨에 도포 시 실험군의 $\Delta \mathrm{E}^{*}$ 값은 대조 군 인 대조군(7레벨 자색고구마 분말 $0 \%$ 함유)보다 모두 $\Delta \mathrm{E}^{*}$ 값이 미비하지만 증가 되었다. 또한 9 레벨 도포한 실험군의 $\Delta \mathrm{E}^{*}$ 값은 대 조군 인 탈색모보다 $\Delta \mathrm{E}^{*}$ 값이 11.94 증가 되었다. 이는 $\Delta \mathrm{E}^{*}$ 값의 산출에서 $\mathrm{L}^{*}, \mathrm{a}^{*}, \mathrm{~b}^{*}$ 을 동시에 보는 것으로서 9 레벨의 명도가 7 레벨 의 실험군보다 높아서 나온 결과로 사료된다. 이는 염색모와 퍼머모 가 시술 중에 받은 화학 처리로 인하여 $\Delta \mathrm{E}^{*}$ 값이 증가한다(Chang, 2016)는 내용과 같은 결과로 나타나는 것을 알 수 있었다. 건강모와 비교 시 실험군 $\Delta \mathrm{E}^{*}$ 값은모두 증가 하였다.

\section{2. 실험군의 물 빠짐 측정}

자색고구마로 도포한 실험군의 물 빠짐 측정 결과는 Table 6 과 같 다. 물 빠짐 측정을 위해서는 모든 실험군을 사용하지는 않고, 가장 명도가 높은 9 레벨의 실험군 만 대표적으로 물 빠짐 측정을 하였다. 이는 9 레벨의 모발이 손상이 7 레벨보다 손상이 심하기 때문에 제조 한 모질 개선제의 물 빠짐이 가장 심할 것으로 판단하였기 때문이 다. 측정결과 1 일차에는 가장 많이 $3.42 \mathrm{NTU}$ 가 빠졌고, 3 일차에는 더 이상의 물 빠짐이 없었다. 자색고구마 분말이 모표피, 모피질에 흡착 침투되었으나 이는 이온결합으로 인한 염착 효과의 약함과 모 발손상으로 인한 염색소의 유실이 커지는 결과로 물에 의해 씻겨 나 간 결과로 사료된다. 염 색소가 부착되는 원리로 약 알칼리성 반영 구 염모제에 비해 모발 손상이 적은 반면 색소 손실이 비교적 빠르 다(Chae et al., 2009)는 결과와 같이 2일차에 물 빠짐이 모두 씻겨 나가 3 일차에는 물 빠짐이 없었다.

\section{3. 실험군의 인장강도 측정}

자색고구마 분말 색소를 함량을 $0 \%, 6 \%, 9 \%, 12 \%$ 달리하여 제조 한 모질 개선제로 실험군에 도포하여 분석한 인장강도 결과는 Table 7 과 같다.

인장강도 측정결과 자색고구마 함량 별 7 레벨의 $6 \%, 9 \%, 12 \%$ 실 험군의 인장강도 변화는 $0 \%$ 함유한 대조군(7레벨 자색고구마 분말 $0 \%$ 함유)보다 미비한 증가를 보였지만 큰 차이는 없었다. 이는 자색 고구마 분말이 모질 개선 효과가 미비하지만 있는 것으로 사료된다. 9 레벨의 실험군은 탈색모인 대조군 보다 오히려 인장강도가 낮았다. 이는 탈색을 2 번하는 동안 모발의 손상이 더 심해짐에 따른 결과로 사료된다. 또한 자색고구마 함량 별 7 레벨의 $6 \%, 9 \%, 12 \%$ 실험모 보다도 $12 \%$ 함유한 9 레벨 실험군의 인장강도가 낮았다. 이는 모발 의 손상을 가장 많이 초래하는 탈색제에 의해 모표피 내의 세포막복 합체 유실과 함께 모피 간충물질 유실로 인장강도가 저하된다는 결 과와 또한 모발은 화학적으로 단백질 중의 시스틴 함량이 감소하여 물리적으로 인장강도가 감소한다는 Oh \& Choe (2012)내용과 같은 결과이다. 건강모와 비교 시 실험군의 인장강도는 모두가 낮음을 알 수 있었다. 이는 모발 손상에 의한 것이다.

\section{4. 실험군의 메틸렌블루를 이용한 흡광도 측정}

자색고구마로 도포한 실험군의 메틸렌블루의 흡광도 측정결과는 Table 8과 같다.

정확한 측정 결과를 위해 총 3 회 측정값의 평균값을 내었다. 흡광 도 측정 결과 자색고구마 분말 함량 별 7 레벨의 $6 \%, 9 \%, 12 \%$ 실험 군의 흡광도 변화는 $0 \%$ 함유한 대조군(7레벨 자색고구마 분말 $0 \%$ 함유)보다 감소함을 알 수 있었다. 이는 모발 손상방지제로 모발의 모피질 내부를 채워 모발 손상 방지제 효과(Lim, 2015)와 인삼추출 물이 모발의 손상에 영향을 미치는데 농도에 따라 흡광도의 증가하 는 정도가 줄어든다(Lee \& Ham, 2010)는 내용과 같은 결과가 나왔 다. 이로서 자색고구마 분말로 제조한 모질 개선제가 모질의 개선효

Table 6. Pigment loss

(Unit: NTU)

\begin{tabular}{|c|c|c|c|c|c|c|}
\hline Sample (9 level 12\%) & & 1 day & & 2 day & & day \\
\hline Pigment loss value & & 3.42 & & 2.19 & & 0 \\
\hline Table 7. Tensile stre & & & & & & (Unit: kgf/mm \\
\hline Sample & Virgin hair & 7 level 0\% & 7 level $6 \%$ & 7 level 9\% & 7 level $12 \%$ & 9 level 12\% \\
\hline Tensile strength value & 1.41 & 1.09 & 1.22 & 1.19 & 1.21 & 0.96 \\
\hline
\end{tabular}

Table 8. Optical density value

(Unit: Abs)

\begin{tabular}{lcccccc}
\hline Sample & Virgin hair & 7 level 0\% & 7 level 6\% & 7 level 9\% & 7 level 12\% & 9 level 12\% \\
Optical density value & 0.064 & 0.108 & 0.081 & 0.082 & 0.081 & 0.092 \\
\hline
\end{tabular}

Table 9. Gloss meter value

(Unit: GU)

\begin{tabular}{lcccccc}
\hline Sample & Virgin hair & 7 level 0\% & 7 level 6\% & 7 level 9\% & 7 level 12\% & 9 level 12\% \\
Gloss meter value & 0.40 & 0.90 & 0.82 & 0.85 & 0.87 & 1.22 \\
\hline
\end{tabular}


과가 있는 것을 알 수 있었다. 그러나 자색고구마 분말 $12 \%$ 함유한 7 레벨과 9 레벨의 실험군 흡광도 차이는 9 레벨의 실험군이 0.011 높 았다. 이는 2 번의 탈색으로 모발 손상이 7 레벨보다 심하여 이러한 결과가 나온 것으로 사료된다. 건강모와 비교 시 실험군의 흡광도는 모두 높음을 알 수 있었다. 이는 손상된 탈색모에 의한 결과이다.

\section{5. 실험군의 광택 측정}

자색고구마로 도포한 시료의 광택 측정결과는 Table 9 와 같다. 광 택 측정 결과 자색고구마 함량 별 7 레벨의 $6 \%, 9 \%, 12 \%$ 실험군의 광택 변화는 $0 \%$ 함유한 대조군(7레벨 자색고구마 분말 $0 \%$ 함유)보 다 감소함을 알 수 있었다. 이는 일반적으로 샴푸 등의 세정으로 윤 기가 감소되는 현상(Kim \& Park, 2013)의 내용과 같은 결과이지만 본 연구의 결과는 세정과 자색고구마의 분말의 컬러에 의해 감소 한 것으로 사료된다. 그러나 자색고구마 $12 \%$ 의 9 레벨 실험군은 대조군 과 자색고구마 분말 $12 \%$ 의 7 레벨의 실험군 보다 광택이 높게 나타 났다. 이는 2 번의 탈색으로 모발 시료가 밝은 색으로 변하여 광택에 영향을 준 것으로 사료된다. 이 결과 자색고구마 분말을 함유한 모 질개선제는 광택에는 큰 영향을 미치지 않는 것을 알 수 있었다. 건 강모와 비교 시 실험군의 광택 정도는 모두 높음을 알 수 있었다.

\section{Conclusion}

본 연구는 모발의 손상을 줄이면서 염색 효과와 모질 개선 효과 를 동시에 볼 수 있는지에 대하여 연구하였다. 염색 효과를 보기 안 토시아닌 색소를 함유한 자색고구마 분말을 사용하였다. 자색고구 마 분말을 $0 \%, 6 \%, 9 \%, 12 \%$ 로 함량을 다르게 하여 모질 개선제를 제조하였다, 시료는 대조군, 실험군 시료에 제조한 모질 개선제를 도포한 후 열처리를 $10 \mathrm{~min}$ 과 자연방치 $10 \mathrm{~min}$ 로 방치 한 후 플레 인 린스 하여 자연 건조하였다. 건조한 실험군 별로 염색 효과를 측 정하고자 $\mathrm{L}^{*}, \mathrm{a}^{*}, \mathrm{~b}^{*}$ 값과, $\Delta \mathrm{E}^{*}$ 값과, 물 빠짐 값을 비교 분석하였고, 모질의 개선 정도를 알기 위해 인장강도, 메틸렌블루를 이용한 흡광 도, 광태 측정을 하였다. 그 결과 다음과 같은 결론을 얻었다.

첫째, 염색 효과를 알기 위한 $\mathrm{L}^{*}, \mathrm{a}^{*}, \mathrm{~b}^{*}$ 값 측정 결과로 $\mathrm{L}^{*}$ 값은 자 색고구마 분말로 염색한 실험군의 $\mathrm{L}^{*}$ 값은 대조군(7레벨 자색고구 마 분말 $0 \%$ 함유)와 비교하여 각각의 7 레벨에서 $6 \%, 9 \%, 12 \%$ 함유 한 실험군의 $\mathrm{L}^{*}$ 값은 감소하는 것을 확인 할 수 있다. 같은 레벨에서 자색고구마 분말 함량이 많을수록 L*값은 감소하는 것을 확인 할 수 있었고 감소폭은 미비하게 나타나 염색 효과는 크지 않은 것을 알 수 있었다.

모발의 표면 색상 분석 결과 $a^{*}$ 와 $b^{*}$ 값은 자색고구마분말을 함량 별로 다르게 제조하여 7레벨에 도포한 실험군의 $a^{*}$ 값은 대조군 보다 모두 $a^{*}$ 값이 + 로 미비하지만 증가 되었다. $b^{*}$ 값은 대조군 보다 모
두 $b^{*}$ 값이 +로 미비하지만 증가 되었다. 그러나 9 레벨 도포한 실험 군의 $b^{*}$ 값은 대조군보다 $b^{*}$ 값이 감소 되었다. $a^{*}$ 와 $b^{*}$ 값 역시 $\mathrm{L}^{*}$ 값 과 마찬가지로 미비한 차이를 보여 염색 효과가 크지 않은 것을 알 수 있었다. $\Delta \mathrm{E}^{*}$ 값 측정결과는 자색고구마 분말을 함량 별로 다르 게 제조하여 7 레벨에 도포 시 실험군의 $\Delta \mathrm{E}^{*}$ 값은 대조군보다 모두 $\Delta \mathrm{E}^{*}$ 값이 미비하지만 증가 되었다. 또한 9 레벨 도포한 실험군의 $\Delta$ $\mathrm{E}^{*}$ 값은 대조군보다 $\Delta \mathrm{E}^{*}$ 값이 11.94 증가 되었다.

둘째, 염색 효과를 알기 위한 물 빠짐 측정 결과로는 1 일차에는 가장 많이 $3.42 \mathrm{NTU}$ 가 빠졌고, 3 일차에는 더 이상의 물 빠짐이 없 었다. 물 빠짐 결과로는 염색 시 염색 도포 효과가 있다는 것을 알 수 있었다.

셋째, 모질의 개선 정도를 알기 위한 인장강도 측정 결과로는 자 색고구마 분말 함량 별 7 레벨의 $6 \%, 9 \%, 12 \%$ 실험군의 인장강도 변화는 $0 \%$ 함유한 대조군(7레벨 자색고구마 분말 $0 \%$ 함유) 보다 미 비한 증가를 보였지만 큰 차이는 없었다. 이는 자색고구마 분말이 모질 개선 효과가 미비하지만 있는 것을 알 수 있었다.

넷째, 모질의 개선 정도를 알기 위한 메틸렌블루를 이용한 흡광 도 측정 결과로는 자색고구마 분말 함량 별 7 레벨의 $6 \%, 9 \%, 12 \%$ 실험군의 흡광도 변화는 대조군보다 감소함을 알 수 있었다. 이로서 자색고구마 분말로 제조한 모질 개선제가 모질의 개선효과가 있는 것을 알 수 있었다.

다섯째, 모질의 개선 정도를 알기 위한 광택 측정 결과로는 자색 고구마 분말 함량 별 7 레벨의 $6 \%, 9 \%, 12 \%$ 실험군의 광택 변화는 대조군(7레벨 자색고구마 분말 $0 \%$ 함유)보다 감소함을 알 수 있었 다. 자색고구마 분말을 함유한 개선제는 광택에는 큰 영향을 미치지 않는 것을 알 수 있었다.

이와 같은 결과로 천연 자색고구마 분말 색소를 함유한 개선제로 는 염색 효과와 모질의 개선효과를 동시에 볼 수는 없었다. 합성 염 모제의 문제점을 보완할 수 있는 대안으로 천연 염료 에 대한 연구 와 개발이 활발하게 진행되고 있다. 천연 염료는 합성염료에 비해 복합 성분의 색소를 함유하므로 발색이 자연스럽고, 변·퇴색이 일 어나도 안정된 색감을 나타내며, 염색 조건에 따라 다양한 명도와 색상을 발현할 수 있다는 장점(Kwon et al., 2004)이 있어 차 후 천 연성분을 이용한 염색 효과와 모질 개선 정도를 알기 위한 연구를 하기 위해서는 우선 제조하지 않고 순수 성분을 가지고 연구를 1 차 적으로 먼저 하여 그 효과를 알고 상용화를 위한 차기 연구로 천연 성분을 함유한 개선제 또는 염모제를 제조 사용하여 각각의 효과를 연구 할 필요가 있다고 생각한다.

\section{Author's contribution}

JK designed all experimental investigations, collected purple sweet potato data and wrote the manuscript. 
Author details

Jusub Kim (Professor), Department of Beauty Design, Sangji University, 84 Sangjidae-gil, Wonju-si, Gangwondo 26339, Korea.

\section{References}

Chae HO, Kwan SH, Na MS. Color maintenance of colored hair using shampoo and conditioner. Journal of the Korean Society of Beauty and Art, 10: 45-62, 2009.

Chang $\mathrm{MH}$. Research on the change of hair by an ultraviolet $\mathrm{A}$. Journal of The Korean Society Design Culture, 22: 651268, 2016.

Choi CR, Rhim JW, Park YK. Physiochemical properties of purple-fleshed sweet potato starch. Journal of the Korean Society of Food Science and Nutrition, 29: 1-5, 2000.

Jang AS, Park $\mathrm{CH}$. A study on the hair dyeing and colorfastness using extracts of mulberry. Asian Journal of Beauty and Cosmetology, 13: 237-242, 2015.

Jeong NY, Lim SN, Choi CN. Dyeability of oxidative permanent hair coloring agents and the damage of hair. Textile Coloration and Finishing, 24: 305-312, 2012.

Kim DC, Kim C, In MJ. Antioxidant activities of extracts prepared from sweet potatoes with different flesh colors. Journal of Applied Biological Chemistry, 58: 21-24, 2015.

Kim HH, Kwon TJ. Effect of protease on the morphological properties and dyeability of human hair. Textile Coloration and Finishing, 20: 59-65, 2008.

Kim JS, Lim DJ, Shin HC. Hair coloring mate. League Line, Seoul, p62, 2006.

Kim JS. Dyeing power of coating permanent to utilize a kaoliang pigment. Asian Journal of Beauty Cosmetology, 12: 127-132, 2014.

Kim JS, Yoo SE. Natural dyeing materials from Opuntia humifusa for hair. Asian Journal of Beauty and
Cosmetology, 17: 129-138, 2019.

Kim JS. Coloring power and changes in hair quality from natural pigment from red paprika. Asian Journal of Beauty and Cosmetology, 16: 369-379, 2018.

Kim JS. Hair coloring. Kuhminsa, Seoul, p44-45, 2017.

Kim YS, Park SJ. Application of transglutaminase for hair revitalization.

Journal of the Society of Cosmetic Scientists of Korea, 39: 25-30, 2013.

Kwon MS, Jeon DW, Choi IR, Kim JJ. A study on natural dyeing using Caesalpinia sappan: mordanting effect of rice straw ash solution. The Research Journal of the Costume Culture, 12: 908-917, 2004.

Lee HN, Ham MY. Hair damage rates and morphological changes from application of a reducing agent prescribing Ginseng extract. Asian Journal of Beauty and Cosmetology, 21: 211-224, 2010.

Lee JS, Ahn YS, Kim HS, Chung MN, Boo HO. Proximate composition and minerals, phenolics, anthocyanins pigment characteristics on the parts of sweet potato. The Journal of the Korean Society of International Agriculture, 19: 196-204, 2007.

Lim DJ. 3-Step hair dye to hair damage effects. Asian Journal of Beauty and Cosmetology, 50: 743-749, 2015.

Min MJ, Choi MH, Kim GC, Shin HJ. Damage prevention effect of green tea seed oil on colored and decolored hair. Korean Society for Biotechnology and Bioengineering Journal, 28: 287-294, 2013.

Oh HJ, Jung YJ. Analysis of natural dye-based hair coloring. The Eastern Art, 37: 164-184, 2017.

Oh MS, Choe TB. Determination of hair damage index using methylene blue staining method. Journal of the Korean Society of Cosmetology, 18: 531-537, 2012.

Yoo SE, Choi WJ. A study of hair dyeing using natural Gardenia (Gardenia jasminoides Ellis) yellow pigment and electrolyzed water and changes in hair color. Journal of the Korean Society of Beauty and Art, 18: 189-201, 2017. 


\section{국문초록}

\section{자색고구마의 염색 효과와 모질 개선효과 연구}

김주섭

상지대학교 뷰티디자인학과, 강원도 원주시, 한국

목적: 본 연구는 안토시아닌 성분이 함유된 자색고구마 분말로 모질 개선제를 제조하여 천연염색의 원료로 사용가능한지를 알아보 고자 염색 효과를 연구하고, 모질의 개선에 영향을 주는 지를 알아보고자 하였다. 방법: 자색고구마 분말 함량을 $0 \%, 6 \%, 9 \%, 12 \%$ 로 다르게 하여 모질 개선제를 제조하였다. 제조한 개선제로 탈색한 시료 모발에 도포 후 열처리와 자연방치를 한 후에 실험군와 대 조군을 측정하여 비교 분석하였다. 염색 효과를 알기 위해 색차계를 이용하여 $\mathrm{L}^{*}, \mathrm{a}^{*}, \mathrm{~b}^{*}, \Delta \mathrm{E}^{*}$ 값과 물 빠짐 정도를 측정하였다. 또 한 모질 개선 효과를 알기 위해 인장강도, 메틸렌블루를 이용한 흡광도, 광택을 측정하였다. 결과: $\mathrm{L}^{*}, \mathrm{a}^{*}, \mathrm{~b}^{*}, \Delta \mathrm{E}^{*}$ 측정 결과는 7 레 벨의 실험군의 $\mathrm{L}^{*}$ 값은 자색고구마 함량이 증가할수록 감소함을 알 수 있었다. $\mathrm{a}^{*}, \mathrm{~b}^{*}$ 값은 대조군 보다는 미비하지만 증가하였다. $\Delta$ $\mathrm{E}^{*}$ 값은 대조군 보다 미비하지만 증가하였다. 물 빠짐 측정 결과는 9 레벨의 실험군이 3 일차에 물 빠짐이 없었다. 인장강도 측정결과 는 실험군이 탈색 모보다 미비하지만 증가하였다. 메틸렌블루를 이용한 흡광도 분석결과 실험군이 대조군 보다 감소하였다. 광택 측정결과는 실험군이 대조군 보다 감소하였다. 결론: 자색고구마 분말로 제조한 모질개선제로는 동시에 염색 효과 및 모질 개선 효 과가 미비하였다. 차후 상용화를 위해서는 더 많은 연구가 필요하다고 생각한다.

핵심어: 자색고구마, 모발, 염색효과, 모질, 손상록

\section{참고문헌}

권민수, 전동원, 최인려, 김종준. 소목 천연 염색에 관한 연구 II: 잿물의 매염효과에 대하여. 복식문화연구, 12 : $908-$ 917, 2004.

김동청, 김재광, 인만진. 육질색 고구마 추출물의 항산화 활성. 한국응용생명화학회지, $58: 21-24,2015$. 김윤석, 박수진. 모발 개선을 위한 Transglutaminase의 적용. 대한화장품학회지, 39: 25-30, 2013. 김주섭, 임대진, 신홍철. 헤어컬러링메이트. 리그라인, 서울, $\mathrm{p} 62,2006$.

김주섭. 고량색소를 첨가한 코팅퍼머제의 염색효과. 아시안뷰티화장품학술지, 12: 127-132, 2014. 김주섭. 헤어 컬러링. 구민사, 서울, p44-45, 2017.

김주섭. 천연 적색 파프리카 색소에 의한 모발 염색려과 모질의 변화. 아시안뷰티화장품학술지, 16: 369-379, 2018.

김주섭, 유세은. 백련초의 모발에 대한 천연염색 원료 연구. 아시안뷰티화장품학술지, 17: 129-138, 2019.

김홍희, 권태종. 프로테아제 처리가 모발의 염색성 및 형태적 특성에 미치는 영향. 한국염색가공학회지, 20: 59-65, 2008.

민명자, 최문희, 김귀철, 신현재. 녹차씨 오일 염색 및 탈색된 모발의 재손상 및 탈색 방지에 미치는 영향. 한국생물공학회 지, 28: 287-294, 2013.

이준설, 안영섭, 김학신, 정미남, 부희옥. 고구마 부위별 일반 및 미네랄, 페놀화합물, 자색색소의 성분 특성. 한국국제농 업개발학회지, 19: 196-204, 2007.

이하나, 함미영. 인삼 추출물을 처방한 환원제 적용에 따른 모발 손상도 및 형태학적 변화. 아시안뷰티화장품학술지, 21: 211-224, 2010.

임대진. 3제형 산화 염모제가 모발손상에 미치는 영향. 아시안뷰티화장품학술지, 50: 743-749, 2015.

오명숙, 최태부. Methylene Blue 염색법을 이용한 모발손상지수의 결정. 한국미용학회지, 18: 531-537, 2012. 오현주, 정연자. 천연 염료를 이용한 모발 염색 연구. 동양예술, 37: 164-184, 2017. 
유세은, 최원준. 천연치자(Gardenia jasminoides Ellis) 황색소와 전해수를 이용한 모발의 염색 및 변화 연구. 한국인체미 용예술학회지, 18: 189-201, 2017.

장미화. 자외선A에 의한 모발 성질의 변화에 관한 연구. 한국디자인문화학회지, 22: 561-568, 2016.

장애선, 박철호. 오디(Mulberry) 추출물의 모발 염색 및 견뢰도 연구. 아시안뷰티화장품학술지, 13: 237-242, 2015.

정남영, 임순녀, 최창남. 산화형 영구염모제 종류에 따른 염색성과 모발의 손상. 한국염색가공학회지, 24: $305-212$, 2012.

최차란, 임종환, 박양균. 자색고구마의 이화학적 특성. 한국식품영양과학회지, 29: $1-5,2000$.

채희옥, 권세화, 나명석. 세정제에 따른 염색모발의 착색 및 유지. 한국인체미용예술학회지, 10: 45-62, 2009. 


\section{中文摘要}

\section{紫色甘薯对染发和改善头发质地的作用}

金周焂

尚志大学美容学科, 江原道原州市, 韩国

目的: 探索通过用含有花青素的紫色甘薯粉制造头发质改善剂，检验是否可以用作天然染发剂。方法: 使用不同 浓度的紫色红薯粉（如0\%，6\%，9\%和12\%）生产头发质地改善剂。将改进剂涂在漂白的样品头发上后，将其 加热并置于自然状态。然后, 进行实验组和对照组的比较分析。为了确认染发的效果, 使用色差标度测量色差 值和褪色程度。另外, 为了了解染色对改善头发质地的作用, 我们使用拉伸强度和亚甲基蓝测量了吸光度和光 泽。结果: 随着紫甘薯浓度的增加, 实验组第 7 级的 L“值降低。与对照组相比, a 和b*的增加不明显。而且, 与漂 白的头发相比, $\Delta \mathrm{E}^{*}$ 的增加不显着。褪色效果显示, 第9级的实验组在第三天没有褪色。此外, 与对照组相比, 实验组没有显示出明显的拉伸强度增加。此外, 与对照组相比, 实验组显示出吸光度降低。最后, 实验组的光 泽明显低于对照组。结论: 紫甘薯粉生产的毛发改善剂对染发和毛发改善没有明显作用。在其可能的商业化之 前, 应进行更多的研究。

关键词: 紫色甘薯, 头发, 染料效果, 头发质地, 伤害 